\title{
The impact of a progressive muscular relaxation exercise programme for reducing insomnia in an elderly population: results from a preliminary study at two elderly homes in the Colombo District of Sri Lanka
}

\author{
W. Jayarathne ${ }^{1}$ and Piyanjali de Zoysa ${ }^{2 *}$ \\ ${ }^{1}$ Allied Health Sciences Unit, University of Colombo, Colombo, Sri Lanka. \\ ${ }^{2}$ Clinical Psychology, Department of Psychological Medicine, Faculty of Medicine, University of Colombo, Colombo, Sri Lanka.
}

\begin{abstract}
Late life insomnia is associated with various physical and psychological conditions, which warrants particular attention. This study aimed at exploring the impact of a programme of relaxation and deep breathing exercises in reducing insomnia in a population of older persons. A group controlled experimental study design was used with a sample of 98 ( 84 females) older persons, aged over 65 years, in two elderly homes. The intervention consisted of progressive muscular relaxation exercises and deep breathing exercises conducted over a 12 week period. Pre- and post-intervention data was collected using the Sinhala version of the Athens Insomnia Scale (AIS). Independent sample t-tests and Paired sample t-tests were performed. Results revealed a significant reduction in insomnia after the intervention in the experimental group, but not in the control group. Hence, this study indicates that relaxation exercises significantly reduce insomnia and increase the quality of sleep among elderly persons. The fact that such a cost effective and easy to implement programme was effective in the treatment of insomnia is an encouraging outcome of this study. Such programmes are useful in countries such as Sri Lanka where monetary and trained human resources are scarce.
\end{abstract}

Keywords: Insomnia, elderly, relaxation exercises, sleep quality, elderly homes.

\section{INTRODUCTION AND LITERATURE REVIEW}

The world population has significantly aged since the mid twentieth century. This is largely due to a demographic transition - a process whereby a reduction in mortality is followed by a reduction in fertility (United Nations, 2013).

Although the definition of an elderly person may vary from country to country, the United Nations has stipulated that an individual of $60+$ years of age be considered an old person (Weinberger, 2001). The age of 60 to 65 is roughly equivalent to the retirement age in most developed countries and it seems to begin at the point where active contribution is no longer possible (Gormen, 2000). With the elderly population growing in the world, factors associated with increasing the quality of life of those in this age group need to be explored. The present study explored one such factor: insomnia and quality of sleep.

Insomnia is a sleep disorder that is characterised by difficulty in falling and staying asleep. Generally, people with insomnia have one or more of the following symptoms: difficulty in falling asleep; non-continuous sleep; difficulty in falling back to sleep; waking up too early in the morning; feeling tired upon waking; feeling exhausted throughout the day; and feeling sleepy during daytime (Chanin, 2012). Many studies have suggested that there is a high incidence of insomnia among older people. For instance, it has been shown that $15 \%$ of older persons suffer from symptoms of insomnia (Foley et al., 1999). This study also revealed that older people who have symptoms of insomnia also have a depressed mood, respiratory symptoms and poor physical health. Hohagen et al. (1994) has reported slightly higher rates of insomnia: $23 \%$ severe, $17 \%$ moderate and $17 \%$ mild insomnia. Insomnia in old age is also reported to impair cognitive abilities, affect relationship with friends and family, and contribute to a feeling of being unwell (Ancholi et al., 2005). These studies suggest that insomnia in late life is associated with a considerable burden to the individual. Further, freedom from family responsibilities and work schedules and lack of exercise may increase the risk of 
insomnia in old age. The presence of illnesses such as depression and dementia and physical conditions such as cardiovascular and respiratory diseases may further compound the problem (Downie, 1993).

The present authors opine that the busy life of present-day society offers less chance for younger people to care for the older generation. This may make elderly people isolated and alone. It is possible that in many countries, including Sri Lanka, this situation has led to the proliferation of elderly homes. Elderly homes are institutions, which accommodate older people, in groups, and are cared for by paid staff. They may be commercial or charitable in nature. The present authors observed that in Sri Lanka, some elders enter these homes by their own decision whilst most others do so according to the wishes of their younger generation. Despite being in the care of paid staff, the isolation from one's family may impact these persons' psychological wellbeing (Jongenelis, 2004). This might be one reason for the increased number of elderly persons diagnosed with insomnia among those living in these homes. If a cost effective and efficient intervention to manage late-life insomnia can be implemented, it would be highly beneficial to both the older persons as well as to his/her caregivers. These benefits would be physiological, psychological and economical (Ellenbogen, 2005).

The present study explored the effects of progressive muscular relaxation (PMR) exercises on elderly people diagnosed with insomnia. Progressive muscular relaxation is a systemic approach to relieve muscle tension by promoting rest and relaxation of muscles, from the feet to the head (Jacobson, 1929). PMR is practised by sequential tensing and relaxing of major skeletal muscle groups (Cooke, 2013). This technique is used in the management of many physical and psychological conditions. For instance, a study in India found that PMR is an effective therapy for improving psychological health and quality of life in patients (Dehdari et al., 2009). PMR has also shown to significantly lower patients' perception of stress, and to enhance the perception of health. The same study also indicated that PMR is effective for those diagnosed with essential hypertension (Sheila et al., 2003). PMR has also shown to be effective in reducing seizures in patients with epilepsy (Cathryne et al., 2005). Importantly, it is also evident to that PMR is effective in the treatment of insomnia in elderly people (Naomi et al., 2008; Scogin et al., 1992).

Although there are similar studies on this topic reported from other parts of the world (e.g. David et al., 1997), no such study have been conducted in Sri Lanka. Though these worldwide findings would be useful in the treatment of insomnia in elderly Sri Lankans, nevertheless, such treatments need to be applied with some caution. This is so because insomnia has a significant psychological basis rooted within the unique socio-cultural milieu of a given country (Roberts et al., 2006). Hence, this firstever Sri Lankan study, on the use of a relaxation exercise programme in the treatment of insomnia in an elderly population, is particularly relevant as it is conducted within the unique cultural milieu of the country. Hence its findings would be particularly applicable in the local context. Further, the intervention used in this study is costeffective, simple and can be easily implemented. This makes it relevant and applicable in developing and middle income countries such as Sri Lanka, where monetary and trained human resources are scarce.

\section{METHOD}

\section{Study design and setting}

An experimental study design was used among residents in two elderly homes in the Colombo District of Sri Lanka. The study sample was divided into two groups: experimental and control. Any exchange of information regarding the intervention, among the two groups, was prevented by selecting participants from different residential sites of the elderly homes. As this was a preliminary study, the elderly homes and the residential sites within these homes were selected as a convenient sample.

\section{Sampling}

At the onset of the study, 120 females and 20 males were interviewed and from them 93 females and 16 males were assessed as having some degree of insomnia. This assessment was made by using the Sinhala version of the Athens Insomnia Scale (AIS: elderly persons who scored 10 or more on the AIS were categorised as having insomnia). Hence, a total of 109 persons were selected for the study (59 in the experimental group). During the study, 11 elderly persons (9 females) withdrew from the experimental group due to difficulties in following the exercise programme on a regular basis. Therefore, the final analysis included 98 persons (48 in the experimental group).

\section{Study instrument}

The self-report Athens Insomnia Scale (AIS: Soldatos et $a l ., 2000)$ was used to obtain pre- and post-intervention data. It has shown good reliability and validity properties (Soldatos et al., 2000). It was translated into the Sinhala language, especially for this study. There are eight 
statements in this questionnaire. Five statements focus on aspects of sleep during the night (e.g. total sleep duration in the night) and the other three items address feeling of wellbeing during the daytime (e.g. physical and mental functioning during the day). There are four response options for each item, from zero to three. Higher the rating, the more significant the sleep problem. Ten is the cut off score for diagnosing insomnia. Although the AIS was supposed to be used as a self-report measure, at the time of data collection the participants found it difficult to understand the items. This was so despite them being literate. This may be because they are not used to fillingin questionnaires. Hence, the first author interviewed the participants individually to help them to complete the AIS.

\section{Study procedure}

Study setting: Two elderly homes in a suburb in the Colombo District of Sri Lanka was chosen for the study. The study population included male and female residents in these two homes who were diagnosed as having insomnia according to the AIS. Older persons who lived in the home for more than six months and who were literate were included. Residents with the following conditions were excluded from the study: severe cognitive impairments, severe cardiac abnormalities, on pharmacological treatment for insomnia, and having a terminal illness. Information on these conditions were obtained from their medical records. Participants were allocated to the experimental and control groups according to their residential site at the home. This was done to prevent information flow between the two groups.

Data collection procedure: Data was collected using the AIS. At the pre-intervention stage, participants whose AIS score was more than 10 was selected for the study. A week after the initial data collection, a progressive muscular relaxation programme was introduced to those in the experimental group. After practicing the exercise programme for a period of 12 weeks, the postintervention data was collected using AIS.

Intervention: Although the PMR exercise programme is recommended to be done in the lying position, due to space limitations (of furniture being stacked around) it was practised in the seated position. This posture too is recommended (Downie, 1993). High chairs with armrests were used. The participants were asked to practise this programme, every day, before bed time, for a duration of 12 weeks. The first author supervised if this was being done during her weekly visits to the home. The matron of the homes too was requested to remind the participants to do the programme.

\section{Data analysis}

Statistical analysis was performed by using SPSS's (Statistical Package for Social Sciences) version 17. A statistically significant reduction in the AIS scores, in the experimental group, from pre- to post-intervention was explored. The independent sample t-test was used for this purpose. Further, it was also explored whether there was a statistically significant difference in the AIS scores, at pre- and post-intervention, between the experimental and control group. The paired sample t-test was used for this purpose.

\section{Ethical considerations}

Ethical clearance was obtained from the Ethics Review Committee of the Faculty of Medicine, University of Colombo. Permission was also obtained from the administrative and management staff of the elderly homes. Written informed consent to participate in the study was obtained from all participants. The first author explained the study specifics, in both Sinhala and English languages. As there were no Tamil or Moslem residents, it was not explained in these languages. The participants were informed of their right to not participate or to withdraw from the study at any time without any explanation. Participants were reassured that their personal details will not be divulged to others without their permission.

\section{RESULTS}

There were $86 \%$ of females in the study sample. The reason for this uneven gender distribution was that there was less number of males, overall, in the selected elderly homes. The age of each individual was difficult to obtain as there were no written document with them to refer to and most of the participants could not recall their actual age.

The cutoff point to indicate insomnia in the AIS is 10 . Therefore, only those persons who scored more than 10 were included in the study. The maximum possible score on the AIS is 24 .

The mean AIS score of the participants (both in the experimental and control groups), at pre-intervention, was $15.39(\mathrm{SD}=2.83)$. These initial AIS scores of the participants was within the normal distribution limits and therefore, the Independent Sample t-test was applied. At the pre-intervention stage, the mean AIS score of the control group $(\mathrm{n}=50)$ was $15.76(\mathrm{SD}=2.96)$ and the mean AIS score of the experimental group $(n=48)$ was $15(\mathrm{SD}=2.67)$. According to the Independent Sample 
t-test, there was no significant difference between the experimental group and control group at this preintervention stage (see Table 1).

Table 1: Score comparison of the experimental and control group at pre-intervention

\begin{tabular}{lrr}
\hline & Experimental group & Control group \\
\hline Mean & 15 & 15.76 \\
$\mathrm{n}$ & 48 & 50 \\
$\mathrm{SD}$ & 2.67 & 2.96 \\
\hline $\mathrm{N}=98 ;$ Mean difference $=0.76 ; \mathrm{T}=1.33 ; \mathrm{Df}=96 ;(\mathrm{p}>0.05, \mathrm{p}=0.18)$
\end{tabular}

At post-intervention too, the AIS scores were within the normal distribution limit. At this stage, the overall mean score was $15.84(\mathrm{SD}=2.84)$ and therefore the Independent Sample t-test was again applied. After the intervention, the mean AIS score of the experimental group $(\mathrm{n}=48)$ was $13.6(\mathrm{SD}=2.76)$ and in the control group $(\mathrm{n}=50)$ it was $15.74(\mathrm{SD}=2.88)$. According to the Independent Sample t-test there was a significant difference between the scores of the experimental and the control groups ( $<<0.05, p=0.000$; see Table 2$)$. These results indicate that the relaxation exercise programme conducted in this study was effective in reducing insomnia and hence in enhancing the quality of sleep in an older population.

Table 2: Score comparison of the experimental and control group at post-intervention

\begin{tabular}{lrr}
\hline & Experimental group & Control group \\
\hline Mean & 13.6 & 15.74 \\
$\mathrm{n}$ & 48 & 50 \\
$\mathrm{SD}$ & 2.76 & 2.88 \\
\hline
\end{tabular}

$\mathrm{N}=98 ;$ Mean difference $=2.14 ; \mathrm{T}=3.74 ; \mathrm{Df}=95.99 ;(\mathrm{P}<0.05$, $\mathrm{p}=0.000)$

The mean score of the experimental group before the intervention was $15(\mathrm{SD}=2.67)$ and after the intervention it was 13.60 ( $\mathrm{SD}=2.76)$. According to the Paired Sample t-test, there was a significant difference between the mean scores before and after the intervention (at $\mathrm{p}<0.01, \mathrm{p}=0.000)$. The mean score of the control group before the intervention was $15.76(\mathrm{SD}=2.96)$ and the post-intervention score (after completing the intervention for the experimental group) was 15.74 $(\mathrm{SD}=2.88)$. According to the Paired Sample t-test there was no significant difference between this pre- and post-intervention scores (at $\mathrm{p}>0.005, \mathrm{p}=0.74$ ).

\section{DISCUSSION}

One hundred and nine (109) of the 140 (i.e. $77.85 \%$ ) elderly persons in the present study was deemed to have insomnia, as indicated by the AIS. This finding cannot be generalised to all elderly persons living in elderly homes in Sri Lanka as this study included only residents in two selected homes. However, it does give an approximate indication of the magnitude of the problem. Since being away from one's family and loneliness could be factors associated with insomnia, the rates obtained here maybe more than in those found in older persons who live with their families. In considering this high prevalence of sleep problems in the study population, other than loneliness being a potential contributing factor, the environment of the elderly home too may have contributed. The homes were situated in an urban setting and its environs were not peaceful.

A study carried out in Cairo, using the same questionnaire as the present study, and in two elderly homes (similar to the present study) has indicated that the prevalence of insomnia among that population was $36.4 \%$ (Bark et al., 2011). The Sri Lankan rate is more than double this figure. In fact, the Sri Lankan rate appears to be the highest when compared to worldwide studies (e.g. Mohomed et al., 2007; Foley et al., 1999) on the rates of insomnia among residents in elderly homes. The reason for this maybe varied: for instance, in other countries the staff may be more helpful to the elderly persons, and the homes may be equipped with better logistical and recreational facilities than in Sri Lanka. However, due to differences in the study methods, study settings and the types of the questionnaires used for data collection, these cross-cultural comparisons would need to be treated with caution.

When carrying out the present study, the first author noted that elderly persons who were involved in activities such as gardening and crafting, which needs increased physical and mental activity, reported lesser levels of insomnia. This was an incidental observation and was not systematically studied. Future studies could explore this dimension. In fact, Montgomery (2002) has emphasised the benefits of physical activities for dealing with sleep problems of the elderly.

The intervention in this study was a programme of progressive muscular relaxation and deep breathing exercises. These exercises have been reported to be effective in reducing insomnia among elders in other parts of the world (Espie et al., 2001). This intervention was carried out every day, for 12 weeks. PMR exercises makes a person aware of voluntary muscle contraction and relaxation of a given muscle group. Doing away with residual muscular tension is the essential feature of this method (Jacobson, 1977). In the present study, the action of only the major muscle groups were examined, as it was difficult for the elders to carry out the entire series 
of muscle actions simultaneously. The time duration of the whole exercise programme was hence reduced to 15 minutes. As suggested in the literature (Jerath et al., 2006), deep breathing exercises were also included in the exercise programme to enhance the effects of relaxation. According to the results of the present study, the PMR exercise programme reduced the level of insomnia in the study population. This finding is in keeping with previous research results (Andrew et al., 2007).

The present research is the first of its kind conducted in Sri Lanka on treating insomnia in an elderly population. The finding of a high level of insomnia among persons living in elderly homes is a matter of concern. The factors affecting this high prevalence of insomnia should be identified and action need to be taken to reduce it. This will be helpful for the elderly persons to have a better quality life. The fact that the intervention used in this study was a simple one, is greatly beneficial. This is so, because the staff at elderly homes could be trained to administer it on the residents (within limitations such as a given elderly person's medical condition). Hence, in developing and middle income countries such as Sri Lanka, where there is a monetary and trained human resource paucity, such an intervention would be very useful.

A limitation of this research was the use of a non-validated, though Sinhala translated version of the AIS. Further limitations were that only two elderly homes were chosen and it was done in a non-random manner. This was so because the study was a time and resource limited preliminary exploration. Future research could be done using a cross-culturally validated AIS, on a larger randomly chosen sample. Also, the AIS was administered on the study participants by the first author. It was initially meant to be a self-administered questionnaire but because the elderly persons found it difficult to fill-in, the first author administered. A more robust future study would overcome this limitation.

\section{REFERENCES}

Ancholi, S., Cooke J. R. (2005) Prevalence and co-morbidity of insomnia and effect of functioning in elderly population. Journal of American Geriatric Society. 53(7 Suppl). pp: S264-71. DOI: http://dx.doi.org/10.1111/j.1532-5415.2005.53392.x

Andrew D. (2007) Treating the health, quality of life and functional impairments in insomnia. Journal of Clinical Sleep Medicine. 3(1). pp: 63-72.

Bark, I. M., Fowzy, N., Abdelaziz, K. M., Khater, M. S. \& Fahim, H. T. (2011) Prevalence of insomnia in older persons living in geriatric homes in Cairo. Egyptian Journal of Community Medicine. 29.
Chanin L. R. (2012) An overview of insomnia [Online] Available from: http:/www.webmd.com/sleep-disorders/ guide/insomnia-symptoms-and-causes\#1 [Accessed: 12 $2^{\text {th }}$ October 2012].

Cooke, H. (reviewed) (2011) Progressive Muscle Relaxation, CAM-Cancer Consortium [Online] Available from: http://www. cam-cancer.org/The-Summaries/Mind-body-interventions/ Progressive-Muscle-Relaxation [Accessed: $2^{\text {nd }}$ July 2011].

Dehdari, T., Heidarnia, A., Ramezankhani, A., Sadeghian, S. \& Ghofranipour, F. (2009) Effects of progressive muscular Relaxation training on quality of life in anxious patients after coronary artery bypass graft surgery. Indian Journal of Medical Research. 129(5). pp: 603-608.

Downie, P. A. (ed) (1993) Caches textbook of general medical and surgical conditions for physiotherapist., pp: 126-127.

Ellenbogen, J. M. (2005) Cognitive benefits of sleep and their loss due to sleep deprivation. Neurology. 64(April 1 of 2). pp: E25-E27.

Foely, D, J., Monjan, A., Simonsick, E. M., Wallace, R. B. \& Blazer, D. G. (1999) Incidence and remission among insomnia among older adults. Journal of Sleep Research and Sleep Medicine. 22(Suppl 2). pp: S366-372.

Gormen, M. (1993) Development and the rights of older people, in Randel, J., German, T. \& Ewing, D. (eds) (1999) The aging and development report, poverty, independence and the world of older people. London: Earthscan publications Ltd. pp: 3-21.

Jacobson E. (1977) You must relax. London: Souvenir Press.

Jacobson, E. (1929) Progressive relaxation. Oxford, England: University of Chicago Press.

Jerath, R., Edry, J. W., Barnes, V. A. \& Jerath, V. (2006) Physiology of long pranaymic breathing. Medical Hypothesis. 67(3). pp: 566-571.

DOI: http://dx.doi.org/10.1016/j.mehy.2006.02.042

Jongenelis, K., Pot, A. M., Eisses, A. M. H., Beekman, A. T. F., Kluiter, H. \& Ribbe, M. W. (2004) Prevalence and risk indicators of depression in elderly nursing home patients. Journal of Affective Disorders. 83(2-3). pp: 135-142. DOI: http://dx.doi.org/10.1016/j.jad.2004.06.001

Kupfer, D. J. \& Reynolds, C. F. (1997) Management of insomnia. The New England Journal of Medicine. 336. pp: 341-346.

DOI: http://dx.doi.org/10.1056/NEJM199701303360506

Makhlouf, M. M., Ayoub, A. I. \& Abdel-Fattah, M. M. (2007) Insomnia symptoms and their correlates among the elderly in geriatric homes in Alexandria, Egypt. Sleep and Breathing. 11(3). pp: 187-194.

DOI: http://dx.doi.org/10.1007/s11325-006-0097-3 
Montgomery, P. \& Dennis, J. (2004) A systematic review of non-pharmacological therapies for sleep problems in later life. Sleep medicine reviews. 8(1). pp: 47-62.

DOI: http://dx.doi.org/10.1016/S1087-0792(03)00026-1

Montgomery, P. \& Dennis, J. (2002) Physical exercise for sleep problems in adults aged 60+. Cochrane Database Systematic Reviews. 4(4). [Online] Available at: http://onlinelibrary.wiley. com/doi/10.1002/14651858.CD003404/full/ $\left[\right.$ Accessed: 12 ${ }^{\text {th }}$ October 2013].

Puskarich, C. A., Whitman, S., Dell, J., Hughes, J. R., Rosen, A. J. \& Hermann, B. P. (1992) Controlled examination of effects of progressive relaxation training on seizure reduction. Epilepsia. 33(4). pp: 675-680.

DOI: http://dx.doi.org/10.1111/j.1528-1157.1992.tb02346.x

Roberts, R. E., Roberts, C. R. \& Chan, W. (2006) Ethnic differences in symptoms of insomnia among adolescents. SLEEP. 29(3). pp: 359-365.

Scogin, F., Rickard, H. C., Keith, S., Wilson, J. \& McElreath, L. (1992) Progressive and imaginal relaxation training for elderly persons with subjective anxiety. Psychology and aging. 7(3). pp: 419- 442 .

DOI: http://dx.doi.org/10.1037/0882-7974.7.3.419

Sheu, S., Irvin, B. L., Lin, H. S. \& Mar, C. L. (2003) Effects of progressive muscle relaxation on blood pressure and psychosocial status for clients with essential hypertension in Taiwa. Holistic Nursing Practice. 17(1). pp: 41-47.

DOI: http://dx.doi.org/10.1097/00004650-200301000-00009

Soldatos, C. R., Dikeos, D. G. \& Paparrigopoulos, T. J. (2000) Athens Insomnia Scale: validation of an instrument based on ICD10 criteria. Journal of psychosomatic research. 48(6). pp: 555-560. DOI: http://dx.doi.org/10.1016/S0022-3999(00)00095-7

United Nations (2013) World Population Aging 2013, ST/ESA/ SER A/348. Department of Economic and Social Affairs.

Weinberger, M. (2001) Personal correspondence. United Nations.

Ziv, N., Rotem, T., Arnon, Z. \& Haimov, I. (2008) The effect of music relaxation versus progressive muscular relaxation on insomnia in older people and their relationship to personality traits. Journal of music therapy. 45(3). pp: 360-380.

DOI: http://dx.doi.org/10.1093/jmt/45.3.360 